Smolders, M., Laurant, M., Verhaak, P., Prins, M., Marwijk, H. van, Penninx, B., Wensing, M., Grol, R. Adherence to evidence-based guidelines for depression and anxiety disorders is associated with recording of the diagnosis. General Hospital Psychiatry: 2009, 31(5), 460-469

\begin{tabular}{|l|l|}
\hline $\begin{array}{l}\text { Postprint } \\
\text { Version }\end{array}$ & 1.0 \\
\hline Journal website & $\underline{\text { http://linkinghub.elsevier.com/retrieve/pii/S0163-8343(09)00098-X }}$ \\
\hline Pubmed link & $\underline{\text { http://www.ncbi.nlm.nih.gov/pubmed/19703640 }}$ \\
\hline DOI & $10.1016 /$ j.genhosppsych.2009.05.011 \\
\hline
\end{tabular}

This is a NIVEL certified Post Print, more info at http://www.nivel.eu

\title{
Adherence to evidence-based guidelines for depression and anxiety disorders is associated with recording of the diagnosis
}

\author{
Mirrian Smolders Ph.D. ${ }^{\text {A, }}$, Miranda Laurant Ph.D. ${ }^{\text {A }}$, Peter VerhaAK Ph.D. ${ }^{\mathrm{B}}$, Marijn Prins \\ M.SC. ${ }^{\mathrm{B}}$, HARM VAN MARWIJK PH.D. ${ }^{\mathrm{C}}$, BRENDA PENNINX Ph.D. ${ }^{\mathrm{D}, \mathrm{E}, \mathrm{F}}$, MiChel Wensing PH.D. ${ }^{\mathrm{A}}$ AND \\ RICHARD GROL PH.D. ${ }^{A}$ \\ aScientific Institute for Quality of Health Care, Radboud University Nijmegen Medical Centre (RUNMC), \\ Nijmegen, The Netherlands \\ bNIVEL, Netherlands Institute for Health Services Research, Utrecht, The Netherlands \\ cDepartment of General Practice, VU University Medical Center, Amsterdam, The Netherlands \\ dDepartment of Psychiatry/EMGO Institute, VU University Medical Center, Amsterdam, The Netherlands \\ eDepartment of Psychiatry, Leiden University Medical Centre, Leiden, The Netherlands \\ fDepartment of Psychiatry, University Medical Centre Groningen, Groningen, The Netherlands
}

\begin{abstract}
Objectives: To assess professionals' adherence to evidence-based guidelines and to investigate whether or not this is influenced by recording of the diagnosis and symptom severity.

Method: Analysis of baseline cross-sectional data of a cohort study of 721 primary care patients with a confirmed diagnosis of a depressive or anxiety disorder. Information on the management of depressive and anxiety disorders was gathered from the electronic medical patient records. Guideline adherence was measured by an algorithm, based on performance indicators.

Results: Forty-two percent of the patients with a depressive disorder was treated in accordance with the guideline, whereas $27 \%$ of the patients with an anxiety disorder received guideline-consistent care. The provision of care in line with current depression and anxiety guidelines was around $50 \%$ for persons with both types of disorders. Documentation of an International Classification of Primary Care diagnosis of depression or anxiety disorder appeared to have a strong influence on guideline adherence. Symptom severity, however, did not influence guideline adherence.

Conclusions: Adherence to depression and anxiety guidelines can be improved, even when the general practitioner makes the diagnosis and records it. Data on actual health care delivery and quality of care provide insight and may be useful in developing quality improvement activities.
\end{abstract}

\section{INTRODUCTION}

Depression and anxiety disorders impose enormous individual and societal burdens owing to their high prevalence rates and substantial associated disability and health care costs [1], [2] and [3]. Both disorders are chronic, often relapsing illnesses, especially if not treated [4] and [5]. Although patients suffering from depressive and anxiety disorders are intensive users of health care services, many patients deny their 
Smolders, M., Laurant, M., Verhaak, P., Prins, M., Marwijk, H. van, Penninx, B., Wensing, M., Grol, R. Adherence to evidence-based guidelines for depression and anxiety disorders is associated with recording of the diagnosis. General Hospital Psychiatry: 2009, 31(5), 460-469

symptoms, use different contextual labels for their distress or do not seek help at all. A complicating issue is that there are many competing demands in the primary care setting where most patients with these conditions are seen [6] and [7].

Due to the abovementioned motives, a substantial number of patients suffering from depressive and anxiety disorders remain unrecognized. Acknowledgement and recognition by both patients themselves and health care providers may need improvement because it allows for adequate treatment that might speed up recovery. The reigning view that the diagnosis of depressive and anxiety disorders conveys additional burden and the stigma attached to having a mental illness are likely to reduce the identification of these illnesses. Nevertheless, there is evidence that adequate recognition is a first important step toward more effective management [8].

Current international guidelines on the management of depression and anxiety disorders recommend both non-pharmacological therapies, such as psychological support and counseling, and pharmacological therapies, such as antidepressant medication, particularly for those with a major disorder [9], [10], [11], [12], [13], [14] and [15]. Provision of guideline-concordant depression care appears to have a beneficial impact on patient outcomes [16], [17] and [18]. In addition, treatment meeting clinical guidelines is also cost effective [19]. Researchers have successfully characterized the quality of care for a variety of somatic disorders [20], [21] and [22], and it is important to provide data to inform policy internationally for psychiatric disorders. However, unlike the situation in diabetes care with the hemoglobin A1c test, there is no laboratory test for the long-term quality of the management of depressive and anxiety disorders in a particular patient.

Several articles on guideline adherence in the management of patients with a depressive or anxiety disorder have already been published [23], [24], [25], [26], [27] and [28]. However, these studies did not address all important aspects of depression and anxiety care, nor did they examine the influence of recording the diagnosis on guideline adherence. Furthermore, the relationship between symptom severity and the degree of guideline adherence has also not yet been investigated. Other aspects of previous studies are that they relied on self-administered modes of data collection and in most cases did not focus on a particular health care setting. In our study, we addressed those limitations. We focused specifically on primary care treatment of depression and anxiety disorders, as those patients are likely to receive most of their care from general medical providers [27], [29] and [30]. Additionally, instead of retrospective selfreport data, we used the electronic medical patient records (EMRs) to establish guideline adherence. The purposes of the present study were: (1) to investigate whether general practitioners (GPs) record the diagnosis of patients with a confirmed Diagnostic and Statistical Manual of Mental Disorders, Fourth Edition (DSM-IV) diagnosis of a depressive or anxiety disorder in the EMRs; (2) to describe the patterns of care received by a cohort of primary care patients suffering from a depressive or anxiety disorder; (3) to assess to which degree GPs adhere to evidence-based clinical guidelines on depression and anxiety disorders and (4) whether or not guideline adherence is influenced by (a) recording of the diagnosis and (b) symptom severity.

\section{METHODS}

\subsection{Study population and setting}

Data for this study came from cross-sectional measurements of the Netherlands Study of Depression and Anxiety (NESDA), an 8-year longitudinal cohort study designed to be representative of persons with depression and anxiety disorders in different health care settings and in different stages of the disorders. Details on objectives, recruitment and methods of NESDA have been described elsewhere [31]. In short, recruitment of participants took place from September 2004 through February 2007. Primary care patients were recruited from 72 GPs in the vicinity of Amsterdam, Leiden and Groningen; 23750 patients (aged 1865 years) who attended their GP in the last 4 months, irrespective of the reason for consultation, were sent a screening questionnaire to measure the presence of affective or anxiety disorders containing the Kessler-10 [32] with five additional questions. Nearly half of the screeners returned $(n=4887)$ were screen-positive, and these persons were interviewed by phone with the short form of the Composite Interview Diagnostic Instrument (CIDI) [33]. If this interview produced a current (6-month recency) depressive disorder (including major depressive disorder or dysthymia) or an anxiety disorder (including generalized anxiety disorder, social phobia, agoraphobia or panic disorder), respondents were asked to participate in NESDA and were invited for a baseline assessment, which included a full CIDI interview. In addition, a random 
Smolders, M., Laurant, M., Verhaak, P., Prins, M., Marwijk, H. van, Penninx, B., Wensing, M., Grol, R. Adherence to evidence-based guidelines for depression and anxiety disorders is associated with recording of the diagnosis. General Hospital Psychiatry: 2009, 31(5), 460-469

selection of the screen-negatives (both from the written screener or the phone-screen) were also invited to participate (control group). The NESDA study was approved by the Central Ethics Committee on Research involving human subjects of the participating institutes. After full verbal and written information about the study, written informed consent was obtained from all participants.

\subsection{Measurements}

\subsubsection{Diagnosis of depressive or anxiety disorder}

The CIDI [World Health Organization (WHO) version 2.1] was used to identify participants with a current (6-month recency) depressive or a current anxiety disorder. Patients with a subthreshold level of a depressive or anxiety disorder were excluded. The CIDI classifies diagnoses according to the DSM-IV criteria [34]. The CIDI is used worldwide and WHO field research has found high interrater reliability [35], high test-retest reliability [36] and high validity for depressive and anxiety disorders [37].

\subsubsection{Patient characteristics}

Detailed sociodemographic data, including age, gender, nationality and marital status were collected by questionnaire. Socioeconomic information was collected by asking for education and income of the participants.

Severity of depressive symptoms was measured with the 30-item Inventory of Depressive Symptomatology (IDS) self-report version. According to established guidelines, we considered scores below 14 to indicate no depressive symptoms or minimal depressive symptoms; $14-25$, mild symptoms; 26-38, moderate symptoms; 39-48, severe symptoms and $>48$, very severe symptoms.

Severity of anxiety symptoms was measured using the 21-item Beck Anxiety Inventory (BAI). We considered scores below 22 to indicate low anxiety; $22-35$, moderate anxiety; and $>35$ severe anxiety.

\subsubsection{Actual GP performance}

Most information on the documentation of the diagnosis depressive or anxiety disorder and the delivery of mental health care by GPs was gathered from the EMRs. Data on diagnosis and treatment were extracted for two years, i.e., from the year prior to inclusion in NESDA to the year after inclusion in NESDA. This data extraction included information on diagnosis, number of GP consultations, type of medication, duration of prescription and referral to primary or secondary specialized mental health care.

\subsubsection{Documentation of depression or anxiety diagnoses}

Information on diagnosis should routinely be recorded by the GP, following the International Classification of Primary Care (ICPC) codes [38]. In the ICPC, two codes deal with depression (P03 and P76) and two codes deal with anxiety (P01 and P74). In our study, patients having an episode P03 and/or P76 were considered to be appropriately diagnosed as depressed by their GP, while patients having an episode P01 and/or P74 were considered to be appropriately diagnosed with an anxiety disorder by their GP. As earlier research demonstrated that GPs often register depressive and anxiety disorders as part of other psychological problems to which the depressive or anxiety disorder is related [39], patients with a CIDI diagnosis depressive disorder and an episode of feeling anxious/nervous/tense (P01), acute stress (P02), feeling/behaving irritable/angry (P04), anxiety disorder (P74), somatization disorder (P75) or neurasthenia/surmenage (P78) in their EMR were considered to be partially recognized as having a depression by their GP, whereas patients with a CIDI diagnosis anxiety disorder and an episode P02, P03, P04, P75, P76 or P78 in their EMR were considered to be partially recognized as having an anxiety disorder by their GP. For the documentation of an appropriate or partial depression or anxiety diagnosis by the GP, we searched the EMRs for the period one year before and 3 months after establishing the CIDI diagnosis.

\subsubsection{Management of depression and anxiety}

Several options are available in the management of depression and anxiety disorders in primary care. GPs have non-pharmacological (psychological support, counseling) and pharmacological (prescription of antidepressant medication) management options. Alternatively, they can refer patients to mental health specialists in primary or secondary health care.

\subsection{Non-pharmacological management}


Smolders, M., Laurant, M., Verhaak, P., Prins, M., Marwijk, H. van, Penninx, B., Wensing, M., Grol, R. Adherence to evidence-based guidelines for depression and anxiety disorders is associated with recording of the diagnosis. General Hospital Psychiatry: 2009, 31(5), 460-469

Information on psychological support, not necessarily including a structured therapy, was obtained by counting the number of GP consultations during a defined period after registration of the above mentioned ICPC codes on depression and anxiety diagnoses.

As the EMRs did not contain information on the provision of counseling, this information was obtained from patient-reported questionnaire data. The Perceived Need for Care Questionnaire (PNCQ) assesses need from the perspective of the patient. Besides questions about perceived needs for care, people are asked if they had contact with different caretakers (for a mental health problem) during the last 6 months. Furthermore, people are questioned about what services they had received for their mental health problem(s). For our study, we used answers to the following specific questions included in the PNCQ: Did you visit your GP during the past 6 months?; Did at least one of these consultations pertain to mental health problems?; Did you receive counseling during these consultations for mental health problems? [40].

\subsection{Pharmacological management}

Information on the prescription of antidepressant medication was recorded according to the Anatomical Therapeutic Chemical (ATC) Classification System [41]. The drugs called antidepressant medication in our study are those with ATC code NO6A.

\subsection{Referral}

Both ICPC codes and Working Committee for Information and Automation codes were used for recording information on referral. In our study, patients whose referral was either marked with ICPC code P01, P02, P03, P04, P74, P75, P76 or P78, or with a WICA code bearing reference to a mental health care professional, were considered to be referred for a depressive or anxiety disorder.

\subsubsection{Quality of care}

\subsubsection{Performance indicators}

A two-round Delphi technique, involving eleven experts in depression and anxiety care, was utilized to develop a set of indicators for the assessment of the quality of general practice care for patients with depression and anxiety disorders. Important stakeholders who were not able to contribute to the Delphi rounds added some additional items for consideration to the results of the Delphi procedure. The performance indicators, based on key recommendations from the national evidence-based clinical depression and anxiety guidelines issued by the Dutch College of GPs [14] and [15], enabled examination of actual health care delivery to primary care patients with depression and anxiety. The performance indicators measured different aspects of depression and anxiety care, including both diagnosis and management of depressive and anxiety disorders. The topics of these performance indicators are presented in Box 1.

\section{[BOX 1]}

\subsection{Statistical analysis}

\subsubsection{Actual performance}

We calculated the percentages of patients with a current depressive disorder or a current anxiety disorder whose EMR contained documentation of an appropriate or partial GP depression or anxiety diagnosis. To describe the patterns of management, we calculated the percentages of patients with a CIDI confirmed depressive disorder, anxiety disorder and comorbid depressive and anxiety disorder (not necessarily also appropriately or partially recognized by their GP) who received (a) psychological support, (b) counseling, (c) antidepressant treatment and (d) referral to specialized mental health care.

\subsubsection{Quality of care}

Based on our performance indicators, we constructed an algorithm for defining adherence to the depression and anxiety guidelines by GPs. Adherence to these guidelines was defined as receiving appropriate psychological support, or receiving counseling, or receiving appropriate antidepressant medication, or a referral to a mental health specialist. 
Smolders, M., Laurant, M., Verhaak, P., Prins, M., Marwijk, H. van, Penninx, B., Wensing, M., Grol, R. Adherence to evidence-based guidelines for depression and anxiety disorders is associated with recording of the diagnosis. General Hospital Psychiatry: 2009, 31(5), 460-469

The sole criterion for appropriate psychological support was the provision of at least five GP consultations in the 15-week period after documentation of the ICPC diagnosis of depression or anxiety. The provision of 1-4 GP consultations in the 15-week period after diagnosing depression or anxiety was considered as suboptimal psychological support. Criteria for appropriate antidepressant medication were (a) the provision of a consultation by the GP within 6 weeks of initiating antidepressant drug treatment and (b) continuation of antidepressant drug treatment for at least five months or cessation of antidepressant drug treatment after 2-6 weeks in case of no response. Antidepressant drug treatment was considered to be suboptimal if it did not include those two additional conditions. Neither counseling nor referral included any additional conditions for appropriate care. The definition of adherence to the anxiety guideline was identical to that of adherence to the depression guideline, with the exception of the element of counseling. In accordance with the Dutch anxiety guideline for GPs [14], counseling was not included in the definition of adherence to the anxiety guideline. The algorithm for guideline adherence is presented in Box 1.

We calculated the percentages of patients who received guideline-consistent treatment. The provision of psychological support could only be calculated for patients who were registered by their GP as having a depression or anxiety disorder as psychological support implied at least five GP consultations in the 15week period after EMR documentation of a depression or anxiety diagnosis by the GP. We performed two subgroup analyses: one analysis to assess the provision of guideline-consistent care to patients with and without documentation of an appropriate or partial ICPC diagnosis in their EMR and another analysis to assess the provision of guideline-consistent care to patients with moderate to very severe symptoms.

The interclass correlation coefficient (ICC) for the provision of guideline-consistent care was assessed to give insight into the proportion of variance that was accounted for by practice level. Statistical analysis was performed using SPSS version 14.0 for Windows.

\section{RESULTS}

\subsection{Study population}

Of the 1610 primary care patients included in NESDA, 743 patients met criteria on the full CIDI interview for either current (6-month recency) depressive disorder or current anxiety disorder. Only 22 of them refused informed consent for the extraction of health care information from their EMR. Our sample included 721 patients from 67 out of 72 GPs. The overall sample had a mean age of 44.9 years (S.D.=12.1) and consisted of 215 men (29.8\%) and 506 women (70.2\%). Nearly all respondents (96\%) had the Dutch nationality, and the majority of the participants $(58.7 \%)$ had an intermediate education. There were nearly equal proportions of married and never-married patients (40.8\% versus $40.2 \%)$. As shown in Table 1,314 participants (43.6\%) were recruited from GPs in Amsterdam, 273 participants from GPs in Leiden (37.9\%) and 134 participants (18.6\%) from GPs in Groningen. There were 148 patients with a depressive disorder only, 298 with an anxiety disorder only and 275 with both disorders. In addition to the characteristics of the whole study sample, Table 1 also shows the above described characteristics separately for patients with a depressive or an anxiety disorder only as well as for patients suffering from both disorders.

\section{[TABLE 1].}

\subsection{Actual GP performance}

\subsubsection{Documentation of depression and anxiety diagnoses}

Table 2 describes the documentation of depression and anxiety diagnoses by the GP in the EMR of patients with a CIDI diagnosis depression and/or anxiety disorder. Only $17.6 \%$ of the patients with a CIDI diagnosis depressive disorder had an EMR documentation of an appropriate or partial depression diagnosis. The proportion of patients with a CIDI diagnosis anxiety disorder and an EMR documentation of an appropriate or partial anxiety diagnosis was even smaller (8.4\%). Compared to patients with a depressive or an anxiety disorder only, patients with both disorders had more often a documentation of an appropriate or partial diagnosis in their EMR (19.7\%).

\section{[TABLE 2.]}

\subsubsection{Management of depression and anxiety}


Smolders, M., Laurant, M., Verhaak, P., Prins, M., Marwijk, H. van, Penninx, B., Wensing, M., Grol, R. Adherence to evidence-based guidelines for depression and anxiety disorders is associated with recording of the diagnosis. General Hospital Psychiatry: 2009, 31(5), 460-469

The various types of care provided to patients with a CIDI depression and/or anxiety disorder, as well as the extent of guideline adherence, are presented in Table 3.

\section{[TABLE 3.]}

Among patients with a depressive disorder only, $16.2 \%$ received some psychological support. $4.7 \%$ of the patients with a depressive disorder was provided at least five consultations in the 15 -week period after documentation of the depression diagnosis in the EMR. Counseling, prescription of antidepressant medication and referral were all offered to one quarter of the patients suffering from a depressive disorder. The majority of patients treated with an antidepressant had a follow-up consultation for medication review within 6 weeks and continued the use of antidepressant medication for at least five months. Forty-four percent of the treated patients with a depressive disorder received only one type of treatment, i.e., psychological support, counseling, antidepressant medication or referral to specialized mental health care. All others who got treatment were provided two or more different types of treatment, either simultaneously or consecutively.

Patients with an anxiety disorder only were less frequently offered some form of treatment; $7.4 \%$ of the patients were seen at least once after documentation of their (partial) anxiety diagnosis. The proportions of patients who received antidepressant medication and a referral to specialized mental health care did not differ substantially (17.8\% and $18.8 \%$, respectively). The majority of the treated patients suffering from an anxiety disorder were offered one type of treatment, whereas $24 \%$ of them received two or more different types of treatment.

Compared to patients with a single diagnosis of a depressive or anxiety disorder, higher treatment rates were found in patients with a comorbid depressive and anxiety disorder. Half of the patients with a comorbid depressive and anxiety disorder who received treatment were offered one type of treatment, whereas the other half of these patients were offered at least two different types of care.

3.2.3. Quality of care

Nearly $42 \%$ of all patients with a CIDI diagnosis depressive disorder was treated in accordance with the guideline (Table 3). When considering the subgroup of patients with a moderate to very severe depressive disorder (based on cutoff scores for the IDS), $47.3 \%$ of the patients were treated in accordance with the guideline. Our study results showed that $80.8 \%$ of the patients with a CIDI diagnosis depressive disorder and an EMR documentation of a (partial) depression diagnosis received any type of guideline-consistent care. In comparison, $33.6 \%$ of the patients with a CIDI diagnosis depressive disorder and no documentation of a depression diagnosis in their EMR received care that was in accordance with the depression guideline.

Of the total patient group with a CIDI diagnosis anxiety disorder, $27.2 \%$ received any type of guidelineconsistent care. For the subgroup of patients with a moderate to severe disorder (based on cut-off scores for the BAI), this percentage was $37 \%$. Again, there was a large difference in guideline adherence regarding patients with and without documentation of a (partial) anxiety diagnosis in their EMR $(60 \%$ and $24.2 \%$, respectively).

Guideline adherence was highest for patients with a comorbid depressive and anxiety disorder (50.2\%). In the subgroup of patients with a moderate to very severe disorder (based on cutoff scores for the IDS and the BAI), this percentage was slightly higher (52.5\%). Although the provision of guideline-recommended care was also in this group markedly different for patients with and without an EMR documentation of their depression or anxiety diagnosis, this difference was smaller compared to the groups of patients with a single diagnosis of a depressive or anxiety disorder $(77.8 \%$ versus $43.4 \%)$.

Clustering of GPs within practices accounted for $13 \%$ of the total variation in GPs' adherence to the depression and anxiety guidelines (ICC=/0.13).

\section{DisCUSSION}

Results of our study indicate that (1) the vast majority of patients with a CIDI diagnosis depressive or anxiety disorder has no EMR documentation of a depression or anxiety diagnosis; (2) nonpharmacological and pharmacological therapies were used equally common in the treatment of patients with individual depressive or anxiety disorders, whereas antidepressant medication was the most frequently used treatment option in the management of comorbid depression and anxiety disorders; (3) adherence to evidence-based depression and anxiety guidelines is $27.2-41.9 \%$ for individual disorders and $50.2 \%$ for comorbid 
Smolders, M., Laurant, M., Verhaak, P., Prins, M., Marwijk, H. van, Penninx, B., Wensing, M., Grol, R. Adherence to evidence-based guidelines for depression and anxiety disorders is associated with recording of the diagnosis. General Hospital Psychiatry: 2009, 31(5), 460-469

depressive and anxiety disorders; (4a) making the diagnosis and recording it is highly associated with guideline adherence and (4b) symptom severity has no strong influence on guideline adherence.

Our results are in line with findings of some earlier studies that pointed to the large number of patients with a psychiatric disorder who remained unacknowledged by their GPs [39] and [42].

A possible explanation for the GPs' low registration rate of depression and anxiety diagnoses might be that primary care, especially for mental health problems, seems to be much less focused on diagnostic categories than on problems or working hypotheses [43]. Depressive and anxiety disorders may be diagnoses that tend to emerge progressively in general practice. GPs' diagnostic strategies may be part of a process to identify those who can benefit from specific interventions. However, as we observed considerably higher rates of guideline adherence in patients with an EMR documentation of their depressive or anxiety disorder (60-81\%) compared to patients without such documentation (24-43\%), we may conclude that diagnosing and subsequent recording of the diagnosis in the patient's EMR is an important prerequisite for the provision of care recommended by the guidelines.

Little is known about why the rates of guideline adherence are so low. As we excluded patients with subtreshold symptoms and minor disorders, our study sample contained only patients with a full-blown depressive or anxiety disorder for whom treatment is recommended by the guidelines. These low rates of guideline adherence may reflect both patients' and physicians' choices. Our rates are slightly higher than the prevalence rates of adequate care found for depression and anxiety disorders in some other studies [23], [25], [26] and [28]. This discrepancy might be explained by differences in the definition of guideline adherence and setting. In the National Comorbidity Survey Replication, for example, the proportion of adequate treatment in the general medical sector was $14.3 \%$ for mood disorders and $13.4 \%$ for anxiety disorders. Adequate treatment was in this study defined as receiving either pharmacotherapy $(\geq 2$ months of an appropriate medication plus $>4$ visits to any type of physician) or psychotherapy ( $\geq 8$ visits with any mental health care or human services professional lasting an average of $\geq 30 \mathrm{~min}$ ) [26].

Finally, the ICC value that we found in the present study was very similar to that observed in previous studies on guideline adherence [44] and [45].

Several limitations of our work deserve mention. The first most important limitation is that we used a yardstick, the CIDI, with perhaps limited clinical relevance for primary care [43]. The CIDI result is independent of whether the patient and GP have actually discussed mood problems or anxiety in the consultation. Second, we were restricted in our calculations because the provision of psychological support could only be calculated for the small number of patients who had a recorded diagnosis of a depressive or anxiety disorder. In addition, some subjects may have only begun antidepressant treatment during our extraction period of two years and did not have sufficient time to fulfill the additional requirement for appropriate treatment, i.e., continuation of medication for at least five months. To the extent that either of this occurred, we may have underestimated the degree of guideline adherence. Secondary analysis, however, showed that this concerned only a small number of patients. Conversely, we may have counted visits in which the respondent's mental health problem was not addressed toward the required number of visits for psychological support, causing us to overestimate the degree of adherence to the guidelines. Furthermore, information about counseling was self-reported by patients. Respondents with a high distress level have been shown to overestimate their mental health service use in self-reported data [46], which possibly also might have led to an overestimation of our study results. Both potential underestimation and overestimation anyhow pertained to only a small proportion of patients and we assume that this had no large influence on our findings. Besides the management options included in our algorithm for guideline adherence, primary care guidelines on depressive and anxiety disorders contain recommendations on some other relevant aspects of depression and anxiety care, for example the assessment of suicide risk and the provision of patient education. As we left some aspects of guideline-recommended care out of consideration in our algorithm, adherence rates to the full spectrum of aspects of guideline-recommended care will presumably be lower than the rates we found in the present study. Our prior research demonstrated, however, that GPs provided patient education and assessed suicide risk of depressed patients in the vast majority of cases [45] and [47].

Finally, the response rate to the initial survey was $45 \%$. Some degree of selection bias cannot be ruled out as responders differed significantly from non-responders with respect to sex and age (i.e., responders were more often female and older than non-responders) [31].

Strong points of our study were a) the use of extensively validated instruments for diagnosing depressive and anxiety disorders as well as measuring their severity; and b) the long period we used for the EMR- 
Smolders, M., Laurant, M., Verhaak, P., Prins, M., Marwijk, H. van, Penninx, B., Wensing, M., Grol, R. Adherence to evidence-based guidelines for depression and anxiety disorders is associated with recording of the diagnosis. General Hospital Psychiatry: 2009, 31(5), 460-469

extraction of the data on diagnosis and treatment. Previous studies such as these have been criticized that the usual longitudinal primary care perspective was missed.

With the strengths and limitations in mind, the results reported here document serious problems in the treatment of primary care patients with depression and anxiety disorders. Despite increasing knowledge about the efficacy of treatments for depressive and anxiety disorders, many of those with a depressive or anxiety disorder fail to receive any type of care in accordance with the guidelines. To properly develop and target quality improvement interventions, it is crucial to understand the reasons why treatment that is obtained fails to conform with evidence-based recommendations. In a separate study on determinants of guideline adherence, we found that a number of both physician- and patient-related characteristics was associated with guideline adherence. Practice-related factors, however, did not seem to influence guideline adherence [48] and [49].

Our results have implications for professionals, people involved in quality improvement and policy makers. Data on actual health care delivery and quality of care provide insight and may be useful in developing quality improvement interventions. Reviews on the management of depression and anxiety disorders have identified a number of efficacious interventions [50], [51] and [52]. Using examples and data from practice appear to be crucial for showing professionals their potential needs for improvement, and to engage them in an active cycle of learning. The current paper shows that actual GP performance can be assessed using their own EMRs. A next step is to feed this information back to GPs. Additionally, other effective strategies aimed at improving the recognition and subsequent EMR documentation of the depression and anxiety disorder should be offered, as this seems to be related to adequate management of these disorders. Besides interactive educational strategies [50], screening for emotional disorders might be helpful, particularly when screening is coupled with system changes that help ensure adequate treatment and follow-up [53].

\section{ACKNOWLEDGMENTS}

The infrastructure for the NESDA study (www.nesda.nl) is funded through the Geestkracht program of the Netherlands Organization for Health Research and Development (ZON-MW, Grant Number 10-000-1002) and is supported by participating universities and mental health care organizations [VU University Medical Center, GGZ inGeest, Arkin, Leiden University Medical Center, GGZ Rivierduinen, University Medical Center Groningen, Lentis, GGZ Friesland, GGZ Drenthe, Scientific Institute for Quality of Healthcare (IQ healthcare), Netherlands Institute for Health Services Research (NIVEL) and Netherlands Institute of Mental Health and Addition (Trimbos)]. Financial support for data-analyses for the present study was provided by ZonMw (Grant Number 945-14-413).

The authors would like to thank Stasja Draisma, Margot de Waal and Willem Jan van der Veen for their help with data collection. The authors also thank the panelists who took part in the Delphi process. Finally, the authors are grateful to the members of the NESDA primary care team.

\section{REFERENCES}

[1] R.V. Bijl, A. Ravelli and G. van Zessen, Prevalence of psychiatric disorder in the general population: results of The Netherlands Mental Health Survey and Incidence Study (NEMESIS), Soc Psychiatry Psychiatr Epidemiol 33 (1998), pp. 587-595.

[2] J.P. Lepine, Epidemiology, burden, and disability in depression and anxiety, J Clin Psychiatry 62 (2001), pp. 4-10.

[3] G. Simon, J. Ormel, M. VonKorff and W. Barlow, Health care costs associated with depressive and anxiety disorders in primary care, Am J Psychiatry 152 (1995), pp. 352-357.

[4] L.S. Goldman, N.H. Nielsen and H.C. Champion, Awareness, diagnosis, and treatment of depression, J Gen Intern Med 14 (1999), pp. 569-580.

[5] K.A. Yonkers, S.E. Bruce, I.R. Dyck and M.B. Keller, Chronicity, relapse, and illness-course of panic disorder, social phobia, and generalized anxiety disorder: findings in men and women from 8 years of follow-up, Depress Anxiety 17 (2003), pp. 173-179.

[6] P.A. Nutting, K. Rost, J. Smith, J.J. Werner and C. Elliot, Competing demands from physical problems: effect on initiating and completing depression care over 6 months, Arch Fam Med 9 (2000), pp. 10591064.

[7] P.A. Nutting, K. Rost, M. Dickinson, J.J. Werner, P. Dickinson and J.L. Smith et al., Barriers to initiating depression treatment in primary care practice, J Gen Intern Med 17 (2002), pp. 103-111. 
Smolders, M., Laurant, M., Verhaak, P., Prins, M., Marwijk, H. van, Penninx, B., Wensing, M., Grol, R. Adherence to evidence-based guidelines for depression and anxiety disorders is associated with recording of the diagnosis. General Hospital Psychiatry: 2009, 31(5), 460-469

[8] G. Simon, D. Goldberg, B.G. Tiemens and T.B. Ustun, Outcomes of recognized and unrecognized depression in an international primary care study, Gen Hosp Psychiatry 21 (1999), pp. 97-105.

[9] Australian Centre for Posttraumatic Mental Health, Australian guidelines for the treatment of adults with acute stress disorder and posttraumatic stress disorder, Victoria, ACPMH, Melbourne (2007).

[10] Institute for Clinical Systems Improvement, Major depression in adults in primary care, Institute for Clinical Systems Improvement, Bloomington (2007).

[11] National Institute for Clinical Excellence, Depression: management of depression in primary and secondary care. Clinical Guideline 23, National Institute for Clinical Excellence, London (2004).

[12] National Institute for Clinical Excellence, Anxiety: management of anxiety (panic disorder, with or without agoraphobia, and generalised anxiety disorder) in adults in primary, secondary and community care. Clinical Guideline 22, National Institute for Clinical Excellence, London (2004).

[13] National Institute for Clinical Excellence, Post-traumatic stress disorder (PTSD): the management of PTSD in adults and children in primary and secondary care. Clinical guideline 26, National Institute for Clinical Excellence, London (2005).

[14] B. Terluin, F.B. van Heest and K. van der Meer et al., Guideline anxiety disorders Dutch College of General Practitioners (first revision), Huisarts en Wetenschap 47 (2004), pp. 26-37.

[15] H.W.J. van Marwijk, H.G.L.M. Grundmeijer, D. Bijl, M.G. van Gelderen, M. de Haan and E.M. van Weel-Baumgarten et al., Guideline depressive disorder Dutch College of General Practitioners (first revision), Huisarts en Wetenschap 46 (2003), pp. 614-623.

[16] K.A. Hepner, M. Rowe, K. Rost, S.C. Hickey, C.D. Sherbourne and D.E. Ford et al., The effect of adherence to practice guidelines on depression outcomes, Ann Intern Med 147 (2007), pp. 320-329.

[17] C.A. Melfi, A.J. Chawla, T.W. Croghan, M.P. Hanna, S. Kennedy and K. Sredl, The effects of adherence to antidepressant treatment guidelines on relapse and recurrence of depression, Arch Gen Psychiatry 55 (1998), pp. 1128-1132.

[18] C.D. Sherbourne, K.B. Wells, N. Duan, J. Miranda, J. Unutzer and L. Jaycox et al., Long-term effectiveness of disseminating quality improvement for depression in primary care, Arch Gen Psychiatry 58 (2001), pp. 696-703.

[19] G. Andrews, C. Issakidis, K. Sanderson, J. Corry and H. Lapsley, Utilising survey data to inform public policy: comparison of the cost-effectiveness of treatment of ten mental disorders, Br J Psychiatry 184 (2004), pp. 526-533.

[20] M.M. Ouwens, R.R. Hermens, R.A. Termeer, S.Y. Vonk Okhuijsen, V.C. Tjan Heijnen and A.F. Verhagen et al., Quality of integrated care for patients with nonsmall cell lung cancer: variations and determinants of care, Cancer 110 (2007), pp. 1782-1790.

[21] C.M. Renders, G.D. Valk, J.J. de Sonnaville, J. Twisk, D.M. Kriegsman and R.J. Heine et al., Quality of care for patients with Type 2 diabetes mellitus-a long-term comparison of two quality improvement programmes in the Netherlands, Diabet Med 20 (2003), pp. 846-852.

[22] W.J. Scholte op Reimer, D.W. Dippel, C.L. Franke, R.J. van Oostenbrugge, G. de Jong and S. Hoeks et al., Quality of hospital and outpatient care after stroke or transient ischemic attack: insights from a stroke survey in the Netherlands, Stroke 37 (2006), pp. 1844-1849.

[23] A. Fernandez, J.M. Haro, M. Martinez Alonso, K. Demyttenaere, T.S. Brugha and J. Autonell et al., Treatment adequacy for anxiety and depressive disorders in six European countries, Br J Psychiatry 190 (2007), pp. 172-173.

[24] M.B. Stein, C.D. Sherbourne, M.G. Craske, A. Means Christensen, A. Bystritsky and W. Katon et al., Quality of care for primary care patients with anxiety disorders, Am J Psychiatry 161 (2004), pp. 2230_ 2237.

[25] P.S. Wang, P. Berglund and R.C. Kessler, Recent care of common mental disorders in the United States: prevalence and conformance with evidence-based recommendations, J Gen Intern Med 15 (2000), pp. 284-292.

[26] P.S. Wang, M. Lane, M. Olfson, H.A. Pincus, K.B. Wells and R.C. Kessler, Twelve-month use of mental health services in the United States: results from the National Comorbidity Survey Replication, Arch Gen Psychiatry 62 (2005), pp. 629-640.

[27] P.S. Wang, S. guilar Gaxiola, J. Alonso, M.C. Angermeyer, G. Borges and E.J. Bromet et al., Use of mental health services for anxiety, mood, and substance disorders in 17 countries in the WHO world mental health surveys, Lancet 370 (2007), pp. 841-850.

[28] A.S. Young, R. Klap, C.D. Sherbourne and K.B. Wells, The quality of care for depressive and anxiety disorders in the United States, Arch Gen Psychiatry 58 (2001), pp. 55-61.

[29] S.J. Katz, R.C. Kessler, E. Lin and K.B. Wells, Medication management of depression in the United States and Ontario,J Gen Intern Med 13 (1998), pp. 77-85.

[30] D.A. Regier, W.E. Narrow, D.S. Rae, R.W. Manderscheid, B.Z. Locke and F.K. Goodwin, The de facto US mental and addictive disorders service system. Epidemiologic catchment area prospective 1-year prevalence rates of disorders and services, Arch Gen Psychiatry 50 (1993), pp. 85-94. 
Smolders, M., Laurant, M., Verhaak, P., Prins, M., Marwijk, H. van, Penninx, B., Wensing, M., Grol, R. Adherence to evidence-based guidelines for depression and anxiety disorders is associated with recording of the diagnosis. General Hospital Psychiatry: 2009, 31(5), 460-469

[31] B.W. Penninx, A.T. Beekman, J.H. Smit, F.G. Zitman, W.A. Nolen and P. Spinhoven et al., The Netherlands Study of Depression and Anxiety (NESDA): rationales, objectives and methods, Int J Methods Psychiatr Res 17 (2008), pp. 121-140.

[32] R.C. Kessler, P.R. Barker, L.J. Colpe, J.F. Epstein, J.C. Gfroerer and E. Hiripi et al., Screening for serious mental illness in the general population, Arch Gen Psychiatry 60 (2003), pp. 184-189.

[33] World Health Organization, Composite International Diagnostic Interview, Core Version 2.1: Interviewer's Manual, World Health Organization, Sydney (Australia) (1997).

[34] American Psychiatric Association, Diagnostic and Statistical Manual of Mental Disorders (4th ed.), American Psychiatric Publishing, Washington, DC (2001).

[35] Wittchen HU, Robins LN, Cottler LB, Sartorius N, Burke JD, Regier D. Cross-cultural feasibility, reliability and sources of variance of the Composite International Diagnostic Interview (CIDI). The Multicentre WHO/ADAMHA Field Trials. Br J Psychiatry 1991;159:645-53, 658.

[36] H.R. Wacker, R. Battegay, R. Mullejans and C. Schlosser, Using the CIDI-C in the general population. In: C.N. Stefanis, A.D. Rabavilas and C.R. Soldatos, Editors, Psychiatry: a world perspective, Elsevier Science Publishers, Amsterdam (2006), pp. 138-143.

[37] H.U. Wittchen, Reliability and validity studies of the WHO-Composite International Diagnostic Interview (CIDI): a critical review, J Psychiatr Res 28 (1994), pp. 57-84.

[38] H. Lamberts and M. Wood, International Classification of Primary Care (ICPC), Oxford University Press, Oxford (1990).

[39] P.F. Verhaak, F.G. Schellevis, J. Nuijen and A.C. Volkers, Patients with a psychiatric disorder in general practice: determinants of general practitioners' psychological diagnosis, Gen Hosp Psychiatry 28 (2006), pp. 125-132.

[40] G. Meadows, C. Harvey, E. Fossey and P. Burgess, Assessing perceived need for mental health care in a community survey: development of the Perceived Need for Care Questionnaire (PNCQ), Soc Psychiatry Psychiatr Epidemiol 35 (2000), pp. 427-435.

[41] WHO Collaborating Centre for Drugs Statistics Methodology. Guidelines ATC classification and DDD assignment (1st ed.), WHO/NCM, Oslo (1996).

[42] C. Thompson, K. Ostler, R.C. Peveler, N. Baker and A.L. Kinmonth, Dimensional perspective on the recognition of depressive symptoms in primary care: the Hampshire Depression Project 3, Br J Psychiatry 179 (2001), pp. 317-323.

[43] Buntinx F, De Lepeleire J, Heyrman J, Fischler B, Vander Mijnsbrugge D, Van den Akker M. Diagnosing depression: what's in a name? Eur J Gen Pract 2004;10:162-5, 168.

[44] B.D. Frijling, C.M. Lobo, M.E. Hulscher, B.B. van Drenth, J.C. Braspenning and A. Prins et al., Provision of information and advice in cardiovascular care: clinical performance of general practitioners, Patient Educ Couns 48 (2002), pp. 131-137.

[45] M. Smolders, M. Laurant, P. Roberge, R. Akkermans, M. Wensing and R. Grol, How well do GPs fulfill their educator role in consultations for depression and anxiety?, Patient Educ Couns 73 (2008), pp. 389395.

[46] A.E. Rhodes and K. Fung, Self-reported use of mental health services versus administrative records: care to recall?, Int J Methods Psychiatr Res 13 (2004), pp. 165-175.

[47] M. Smolders, M. Laurant, R. Akkermans, M. Wensing and R. Grol, GPs' assessment of suicide risk in depressed patients, Prim Care Comm Psychiatr 13 (2008), pp. 138-140.

[48] Prins A, Verhaak PF, Smolders M, Laurant M, van der Meer K, Spreeuwenberg P, et al. Patient factors obstructing and facilitating guideline-compliant care for primary care patients with anxiety or depression. Submitted 2009.

[49] Smolders M, Laurant M, Verhaak PF, Prins A, van Marwijk HWJ, Penninx BW, et al. Which physician and practice characteristics are associated with adherence to evidence-based guidelines for depressive and anxiety disorders? Submitted 2009.

[50] S. Gilbody, P. Whitty, J. Grimshaw and R. Thomas, Educational and organizational interventions to improve the management of depression in primary care: a systematic review, JAMA 289 (2003), pp. 3145-3151.

[51] J. Heideman, E. van Rijswijk, N. van Lin, S. de Loos, M. Laurant and M. Wensing et al., Interventions to improve management of anxiety disorders in general practice: a systematic review, Br J Gen Pract 55 (2005), pp. 867-874.

[52] M. Smolders, M. Laurant, P. Roberge, A. van Balkom, E. van Rijswijk and P. Bower et al., Knowledge transfer and improvement of primary and ambulatory care for patients with anxiety, Can J Psychiatry 53 (2008), pp. 277-293.

[53] M.P. Pignone, B.N. Gaynes, J.L. Rushton, C.M. Burchell, C.T. Orleans and C.D. Mulrow et al., Screening for depression in adults: a summary of the evidence for the U.S. Preventive Services Task Force, Ann Intern Med 136 (2002), pp. 765-776. 
Smolders, M., Laurant, M., Verhaak, P., Prins, M., Marwijk, H. van, Penninx, B., Wensing, M., Grol, R. Adherence to evidence-based guidelines for depression and anxiety disorders is associated with recording of the diagnosis. General Hospital Psychiatry: 2009, 31(5), 460-469

\section{BOX AND TABLES}

Box 1. Main topics of performance indicators on depression and anxiety care

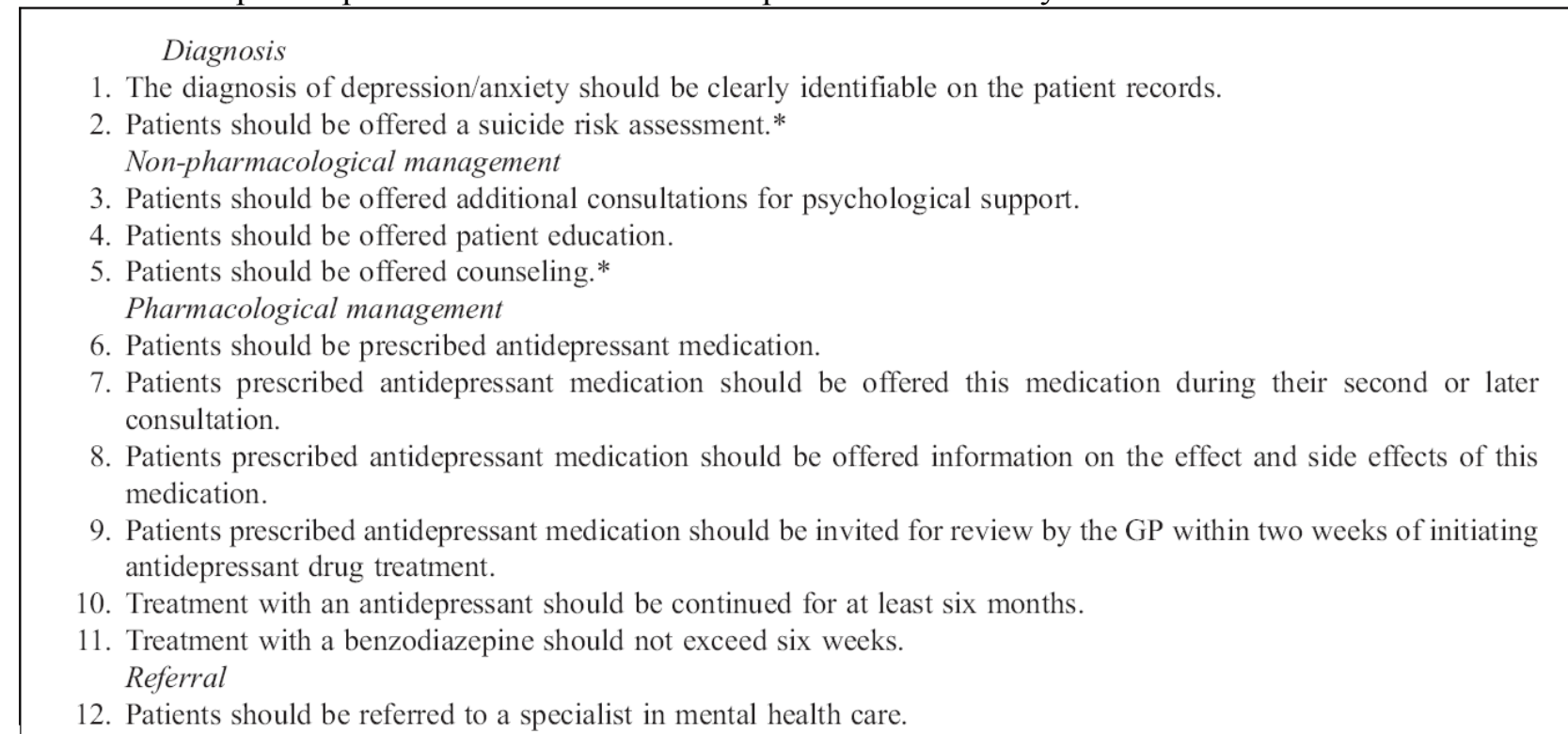

\section{ALGORITHM FOR APPROPRIATE GUIDELINE ADHERENCE}

$>$ PSYCHOLOGICAL SUPPORT including at least five consultations in 15 weeks after documentation of diagnosis OR

$>$ COUNSELING*

OR

$\triangle$ PRESCRIPTION OF ANTIDEPRESSANT MEDICATION including evaluation after 6 weeks of prescription and minimal duration of 5 months or cessation in case of no response OR

$\gg$ REFERRAL TO MENTAL HEALTH SPECIALIST

\section{ALGORITHM FOR PARTIAL GUIDELINE ADHERENCE}

$\triangle$ PSYCHOLOGICAL SUPPORT including one to four consultations in 15 weeks period after documentation of diagnosis OR

$\triangle$ PRESCRIPTION OF ANTIDEPRESSANT MEDICATION without fulfillment of any additional conditions

*Only applicable to GP depression care 
Table 1

Characteristics of the study sample

\begin{tabular}{|c|c|c|c|c|}
\hline Characteristic & Total $(n=721)$ & $\begin{array}{l}\text { Current depressive } \\
\text { disorder }(n=148)\end{array}$ & $\begin{array}{l}\text { Current anxiety } \\
\text { disorder }(n=298)\end{array}$ & $\begin{array}{l}\text { Current depressive disorder and } \\
\text { current anxiety disorder }(n=275)\end{array}$ \\
\hline \multicolumn{5}{|l|}{ Age } \\
\hline Mean \pm S.D. years & $44.9(12.1)$ & $44.2(11.8)$ & $44.9(12.4)$ & $45.3(11.9)$ \\
\hline \multicolumn{5}{|l|}{ Gender, no. (\%) } \\
\hline Male & $215(29.8)$ & $47(31.8)$ & $95(31.9)$ & $73(26.5)$ \\
\hline Female & $506(70.2)$ & $101(68.2)$ & $203(68.1)$ & $202(73.5)$ \\
\hline \multicolumn{5}{|l|}{ Nationality, no. (\%) } \\
\hline Dutch & $692(96.0)$ & $143(96.6)$ & $289(97.0)$ & $260(94.5)$ \\
\hline Other & $29(4.0)$ & $5(3.4)$ & $9(3.0)$ & $15(5.5)$ \\
\hline \multicolumn{5}{|l|}{ Marital status, no. (\%) } \\
\hline Never been married & $290(40.2)$ & $60(40.5)$ & $129(43.3)$ & $101(36.7)$ \\
\hline Married & $294(40.8)$ & $61(41.2)$ & $119(39.9)$ & $114(41.5)$ \\
\hline Living apart & $13(1.8)$ & $0(0.0)$ & $5(1.7)$ & $8(2.9)$ \\
\hline Divorced & $111(15.4)$ & $26(17.6)$ & $39(13.1)$ & $46(16.7)$ \\
\hline Widow(er) & $13(1.8)$ & $1(0.7)$ & $6(2.0)$ & $6(2.2)$ \\
\hline \multicolumn{5}{|c|}{ Income per month, No. (\%) } \\
\hline$<€ 1000$ & $113(15.8)$ & $17(11.6)$ & $41(13.9)$ & $55(20.1)$ \\
\hline$€ 1.000-€ 2.000$ & $250(35.0)$ & $52(35.6)$ & $97(32.8)$ & $101(37.0)$ \\
\hline$€ 2.000-€ 3.000$ & $198(27.7)$ & $44(30.1)$ & $88(29.7)$ & $66(24.2)$ \\
\hline$€ 3.000-€ 4.000$ & $113(15.8)$ & $25(17.1)$ & $50(16.9)$ & $38(13.9)$ \\
\hline$>€ 4.000$ & $41(5.7)$ & $8(5.5)$ & $20(6.8)$ & $13(4.8)$ \\
\hline \multicolumn{5}{|l|}{ Education, No. (\%) } \\
\hline Basic & $68(9.4)$ & $8(5.4)$ & $24(8.1)$ & $36(13.1)$ \\
\hline Intermediate & $423(58.7)$ & $85(57.4)$ & $177(59.4)$ & $161(58.5)$ \\
\hline High & $230(31.9)$ & $55(37.2)$ & $97(32.6)$ & $78(28.4)$ \\
\hline \multicolumn{5}{|l|}{ Region } \\
\hline Amsterdam & $314(43.6)$ & $66(44.6)$ & $126(42.3)$ & $122(44.4)$ \\
\hline Leiden & $273(37.9)$ & $55(37.2)$ & $104(34.9)$ & $114(41.5)$ \\
\hline Groningen & $134(18.6)$ & $27(18.2)$ & $68(22.8)$ & $39(14.2)$ \\
\hline
\end{tabular}


Table 2

Documentation of depression and anxiety diagnoses in EMR

\begin{tabular}{|c|c|c|c|}
\hline & $\begin{array}{l}\text { Patients with a CIDI diagnosis } \\
\left.\text { current }^{\mathrm{a}} \text { depressive disorder ( } n=148\right)\end{array}$ & $\begin{array}{l}\text { Patients with a CIDI diagnosis } \\
\text { current }^{\mathrm{a}} \text { anxiety disorder }(n=298)\end{array}$ & $\begin{array}{l}\text { Patients with both CIDI } \\
\text { diagnoses }(n=275)\end{array}$ \\
\hline Documentation of appropriate diagnosis ${ }^{\mathrm{b}}$ in EMR, no. (\%) & $16(10.8)$ & $14(4.7)$ & 45 (16.4) \\
\hline Documentation of partial diagnosis ${ }^{\mathrm{c}}$ in EMR, no. (\%) & $10(6.8)$ & $11(3.7)$ & $9(3.3)$ \\
\hline No documentation of diagnosis in EMR, no. (\%) & $122(82.4)$ & 273 (91.6) & $221(80.4)$ \\
\hline
\end{tabular}

a Six-month recency.

ICPC codes P03/P76 (depression) or ICPC codes P01/P74 (anxiety disorder)

${ }^{c}$ ICPC codes P01, P02, P04, P74, P75 or P78 (depression) or ICPC codes P02, P03, P04, P75, P76 or P78 (anxiety disorder).

Table 3

Actual provision of depression and anxiety care

\begin{tabular}{|c|c|c|c|c|c|c|c|c|c|}
\hline & \multicolumn{3}{|c|}{$\begin{array}{l}\text { Patients with a depressive } \\
\text { disorder only }\end{array}$} & \multicolumn{3}{|c|}{$\begin{array}{l}\text { Patients with an anxiety } \\
\text { disorder only }\end{array}$} & \multicolumn{3}{|c|}{$\begin{array}{l}\text { Patients with a depressive and an } \\
\text { anxiety disorder }\end{array}$} \\
\hline & $\begin{array}{l}\text { Recorded } \\
\text { (partial) } \\
\text { diagnosis } \\
(n=26)\end{array}$ & $\begin{array}{l}\text { No recorded } \\
\text { diagnosis } \\
(n=122)\end{array}$ & $\begin{array}{l}\text { Total } \\
(n=148)\end{array}$ & $\begin{array}{l}\begin{array}{l}\text { Recorded } \\
\text { (partial) }\end{array} \\
\text { diagnosis } \\
(n=25)\end{array}$ & $\begin{array}{l}\text { No recorded } \\
\text { diagnosis } \\
(n=273)\end{array}$ & $\begin{array}{l}\text { Total } \\
(n=298)\end{array}$ & $\begin{array}{l}\text { Recorded } \\
\text { (partial) } \\
\text { diagnosis } \\
(n=54)\end{array}$ & $\begin{array}{l}\text { No recorded } \\
\text { diagnosis } \\
(n=221)\end{array}$ & $\begin{array}{l}\text { Total } \\
(n=275)\end{array}$ \\
\hline \multicolumn{10}{|l|}{ Psychological support, \% } \\
\hline Appropriate psychological support & 26.9 & n.a. & 4.7 & 8.0 & n.a. & 0.7 & 24.1 & n.a. & 4.7 \\
\hline Suboptimal psychological support & 65.4 & n.a & 11.5 & 80.0 & n.a & 6.7 & 68.5 & n.a & 13.5 \\
\hline No psychological support & 7.7 & n.a. & 83.8 & 12.0 & n.a. & 92.6 & 7.4 & n.a. & 81.8 \\
\hline \multicolumn{10}{|l|}{ Counseling, $\%$} \\
\hline Counseling & 46.2 & 20.5 & 25.0 & n.a. & n.a. & n.a. & 33.3 & 20.8 & 23.3 \\
\hline No counseling & 53.8 & 79.5 & 75.0 & n.a. & n.a. & n.a. & 66.7 & 79.2 & 76.7 \\
\hline \multicolumn{10}{|l|}{ Antidepressant medication, $\%$} \\
\hline Appropriate antidepressant medication & 42.3 & 10.7 & 16.2 & 28.0 & 12.1 & 13.4 & 44.4 & 19.5 & 24.4 \\
\hline Suboptimal antidepressant medication & 23.1 & 4.9 & 8.1 & 16.0 & 3.3 & 4.4 & 18.5 & 7.2 & 9.5 \\
\hline No antidepressant medication & 34.6 & 84.4 & 75.7 & 56.0 & 84.6 & 82.2 & 37.0 & 73.3 & 66.1 \\
\hline \multicolumn{10}{|c|}{ Referral to specialized mental health care, $\%$} \\
\hline Referral & 61.5 & 17.2 & 25.0 & 44.0 & 16.5 & 18.8 & 50.0 & 20.4 & 26.2 \\
\hline No referral & 38.5 & 82.8 & 75.0 & 56.0 & 83.5 & 81.2 & 50.0 & 79.6 & 73.8 \\
\hline \multicolumn{10}{|l|}{ Guideline adherence, $\%$} \\
\hline Appropriate guideline adherence & 80.8 & 33.6 & 41.9 & 60.0 & 24.2 & 27.2 & 77.8 & 43.4 & 50.2 \\
\hline Partial guideline adherence & 19.2 & 3.3 & 6.1 & 36.0 & 2.9 & 5.7 & 16.7 & 4.1 & 6.6 \\
\hline No guideline adherence & 0.0 & 63.1 & 52.0 & 4.0 & 72.9 & 67.1 & 5.6 & 52.5 & 43.2 \\
\hline
\end{tabular}

n.a., not applicable. 